\title{
REPRODUTIBILIDADE TÉCNICA, ARTE E POLÍTICA
}

\section{Marcos Soares ${ }^{1}$}

\begin{abstract}
Resumo: Este ensaio pretende mapear alguns dos momentos-chave do diálogo entre o crítico alemão Walter Benjamin e o dramaturgo Bertolt Brecht a respeito do potencial do cinema como linguagem artística e os riscos que artistas interessados em seu desenvolvimento corriam com a ascensão do nazi-fascismo.
\end{abstract}

Palavras-chave: Benjamin. Brecht. Cinema. Reprodutibilidade. Fascismo.

Uma das principais frentes da crítica pós-moderna é a neutralização da crítica militante, seja por sua desqualificação, seja por sua transformação em nomes e conceitos da moda. Na lista das vítimas, talvez o nome de Walter Benjamin esteja dentre os mais frequentemente citados na crítica de cinema desde o final dos anos 60 , notadamente suas discussões sobre a reprodutibilidade técnica, que frequentemente são utilizadas para celebrar festivamente o "potencial" dos novos meios de comunicação que surgiram a partir do nascimento da fotografia e do cinema. O texto de Benjamin é, assim, frequentemente utilizado na direção oposta da condenação do aparato cinematográfico na sua totalidade efetuado por críticos como Jean Louis Baudry a partir da equação entre as técnicas de dominação da ideologia burguesa e a estrutura "inerente" (o dispositif, diria Baudry) implícita na relação entre filme e espectador, na qual o último é condenado a uma posição de passividade infantilizadora (XAVIER, 1983, pp. 383-402).

Quando o assunto é a questão da reprodutibilidade técnica, até críticos de esquerda competentes tropeçam em mal-entendidos. Michael Löwy, por exemplo, sugere que o texto revela uma adesão pouco crítica às promessas do progresso tecnológico ao afirmar que "ele [Benjamin] parece atraído por uma variante soviética da ideologia do progresso, disposto a reinterpretá-la à sua maneira” (LOWY, 2005, p. 27) enquanto que Fredric Jameson conclui que ele representa uma tentativa de "descrever as capacidades aparentemente neutras da câmera" (JAMESON, 1974, p. 60). Essas opiniões exemplificam uma posição comum na crítica de esquerda sobre o texto de Benjamin, que enxerga uma virtualidade nostálgica, quando não francamente apologética, em seus pontos de vista críticos. Para um crítico marxista o erro teria sido imperdoável, pois equivaleria a supor um desenvolvimento inexorável dos meios de produção (neste caso, artísticos) através do qual a aura da arte tradicional, aquilo que ela retém do âmbito do "sagrado" e do irracional, seria automaticamente destruída em um processo automático, com a nova arte caminhando triunfantemente na direção de usos progressistas, sem levar em conta o aprisionamento a que as relações de produção (neste caso, as corporações que comandam os processos de produção, distribuição e exibição de filmes) submetem esse desenvolvimento.

\footnotetext{
1 Doutor. Professor de Literatura Inglesa e Norte-Americana da Universidade de São Paulo. Lattes: http://lattes.cnpq.br/7249014007309888.
} 
$\mathrm{Na}$ verdade, esse tipo que otimismo ingênuo que muitos dizem identificar nas reflexões sobre a reprodutibilidade técnica era precisamente o tipo de otimismo que Benjamin identificava com as tendências reformistas, quando não abertamente reacionárias, tanto da Social-Democracia alemã quanto do Stalinismo que viria dominar o Partido Comunista mundial após a Terceira Internacional, com sua fé inexorável na ideologia do progresso. Como os leitores das "Teses sobre o conceito de história" sabem, é justamente o pressuposto de um progresso inexorável que se tornaria alvo explícito da crítica de Benjamin.

Porém, quando o texto de Benjamin foi escrito entre 1933-1935, o nazi-fascismo estava em plena ascensão, e, portanto, já havia ficado claro que as experiências que haviam marcado tanto o avanço do movimento operário internacional quanto as experiências estéticas radicais das vanguardas históricas das décadas anteriores (surrealismo, dadaísmo, expressionismo, etc.) chegariam a um fim abrupto e violento. De qualquer modo, do ponto de vista restrito da produção cinematográfica, as restrições já haviam ficado claras para Benjamin muito antes, a partir da leitura do texto de Brecht sobre "O processo dos três vinténs" (1930-32). Nesse texto, Brecht faz um relato e uma análise do processo judicial que moveu contra a indústria cinematográfica a respeito da adaptação para o cinema de sua peça "Ópera dos três vinténs". O inusitado do processo é que Brecht não reclamava que o filme de Pabst não era fiel à peça, mas pelo contrário, que era, por assim dizer, "fiel demais". Na opinião de Brecht, a produção cinematográfica se restringiu à filmagem de algo muito próximo da montagem teatral, desperdiçando o potencial da linguagem do cinema, que poderia avançar enormemente em relação ao texto original (BRECHT, 2000, pp.131-202).

Cabe apontar aqui que, como Brecht sabia bem, o processo era generalizado, isso só para ficarmos no campo das relações entre cinema e literatura dramática: como afirma a crítica Iná Camargo Costa, "a ideia de fazer teatro enlatado para concorrer diretamente com o produto mais prestigiado do show business - o teatro declamado havia sido lançada na França por americanos radicados em Paris (os irmãos Lafitte), enredados até o pescoço com a indústria cultural (jornal e editoras). No ano de 1908 eles realizaram a dupla proeza de lançar um filme com o elenco da Comédia Francesa e, com ele, o gênero do "filme de arte", que desde então é marca comercial" (COSTA, 2012, p. 139). De qualquer modo, como a divisão do mercado mundial já havia sido feita em 1930 entre americanos e alemães e, a partir daí, grande parte da produção, distribuição e exibição de filmes já estava na malha da indústria cultural, não havia razão para ingenuidade.

Digamos, então, para resumir, que tanto para Brecht quanto para Benjamin já estava suficientemente claro que sua intervenção militante no campo das artes deveria ser feita a partir da percepção da lacuna entre as novas capacidades tecnológicas e o processo incompleto de democratização da esfera pública, que havia dado passos importantes com a Revolução Russa e com a organização da classe operária alemã nos anos 20, mas que agora encontrava seu maior obstáculo na ascensão do nazi-fascismo.

É justamente a ascensão do fascismo que vai adensar a percepção de Benjamin sobre a posição peculiar do cinema no debate a respeito do desenvolvimento das forças produtivas e seu aprisionamento pelas relações de produção. Um dos pontos de inflexão 
sobre esse problema já aparece no texto "Sobre alguns temas em Baudelaire". Nele Benjamin argumenta que o cinema é a linguagem moderna por excelência, por ser a mais apropriada para levar adiante a estética do choque que Baudelaire havia introduzido na poesia, pois no cinema "a percepção sob a forma de choque se impõe como princípio formal” (BENJAMIN, 1994, p. 125). Mas também é nesse texto que ele aponta que o ritmo de aprisionamento das forças produtivas produzido pela concentração de capital se acelerava perigosamente. Quando Benjamin se refere à relação entre o desenvolvimento das forças produtivas e a guerra, ele toca num ponto fundamental do processo de desenvolvimento dos meios de comunicação modernos. Numa nota do texto, Benjamin diz: "Quanto mais curto é o tempo de adestramento do operário industrial, tanto mais longo é o dos militares. Talvez faça parte da preparação da sociedade para uma guerra total essa transferência do adestramento da produção para o da destruição" (BENJAMIN, 1994, p. 126).

É a percepção desse contraste que servirá de base implícita para todos os textos de Benjamin sobre cinema. Pois o fortalecimento da indústria cultural e, em seguida, a ascensão do fascismo colocava no horizonte o seguinte problema: grande parte do desenvolvimento das novas tecnologias de reprodução atendia não apenas às demandas de expansão do capital, mas também diretamente às demandas cada vez mais urgentes do aparato militar. Basta pensar no aperfeiçoamento científico realizado na área dos radares, telégrafos, rádios e, mais tarde, nas tecnologias da televisão e da internet para perceber a relação direta. A insistência de Benjamin sobre determinados usos da tecnologia reprodutiva visava, assim, a cobrir a lacuna entre duas temporalidades distintas: de um lado, a temporalidade acelerada do desenvolvimento das novas técnicas, que atendiam às demandas industriais e militares da época; e, de outro, a temporalidade mais lenta da criação dos novos conteúdos que correspondessem ao potencial efetivo das novas tecnologias. Como Benjamin percebeu, essa lacuna colocava grande parte do cinema produzido na época, com suas regras em grande parte baseadas na chamada peça bem feita do teatro comercial burguês do século XIX, numa posição de inferioridade até em relação à poesia de Baudelaire.

Porém, havia na produção cinematográfica mundial dois exemplos extraordinários de realizações que na opinião de Benjamin trabalhavam na criação desses conteúdos. Uma delas era o cinema soviético pós-1917, que na linha das experiências literárias de Tretiakov efetuava pelo menos duas grandes conquistas: de um lado, seguindo os preceitos construtivistas, trabalhava na eliminação das fronteiras entre autores e produtores aos dissolver categorias industriais como roteiro bem feito e atuação profissional, criando uma nova concepção do "real" no centro da produção cinematográfica; de outro, elevava a categoria do choque ao principio formal central, transformando-o numa análise dialética dos conflitos sociais que determinavam os rumos da história recente. Tanto na teoria quanto na prática, o exemplo mais eloquente da junção dos dois princípios apontados acima era o cinema de Sergei Eisenstein, que se tornaria ele próprio vítima da censura stalinista na década de 30 e 40.

Entretanto, o gênero cinematográfico que mais chamou a atenção tanto de Brecht quanto de Benjamin foi a comédia muda norte-americana, notadamente os filmes de Chaplin, nos quais ambos identificavam afinidades eletivas entre o potencial das novas 
tecnologias de reprodução, o teatro épico de Brecht e o surrealismo e que constituíam, portanto, um campo de treinamento de um uso revolucionário dos sentidos. Brecht famosamente apontou em diversos textos que Chaplin era um dos atores de cinema que mais se aproximava do que ele chamava de atuação distanciada: num texto de 1926, ele descreve a cena em que Chaplin come as botas em A corrida do ouro (Gold Rush, 1925), apontando a sequência como um exemplo perfeito de como a abordagem épica poderia transformar um ato cotidiano e naturalizado num evento espantoso, digno de atenção e análise: "Chaplin devora a bota, com bons modos à mesa, removendo o prego como se ele fosse um osso de galinha”. (BRECHT, 2000, p. 10).

Entre 1919 e 1935, Benjamin publicou cinco textos sobre a comédia norteamericana em jornais alemães, quatro deles sobre Chaplin, enquanto o mais conhecido, o último da série, é intitulado "A fórmula na qual a estrutura dialética do filme encontra expressão" (BENJAMIN, 1999, p. 94-95), antes de usar Chaplin uma referência central do texto da reprodutibilidade técnica. Para quem leu os textos de Benjamin sobre o teatro épico de Brecht e sobre o surrealismo, não é difícil imaginar o que o atraia no regime anárquico da comédia: sua estrutura fragmentada e paratática, baseada na autonomia do quadro cômico individual mais do que na linearidade do teatro e do cinema burguês; sua associação entre materiais díspares e sua ênfase numa dialética entre o familiar e o estranho; suas analogias impossíveis, construídas num ritmo desconexo e episódico; sua insistência no uso de objetos arrancados de seus empregos utilitários comuns. Tudo isso caracterizava um modo de despertar um encantamento do mundo, um ponto de partida para um tipo de pensamento distante da razão instrumental, uma "iluminação profana" que não se pautaria pelo que é, mas pelo que poderia ser. Estaria aqui, portanto, formulada uma tentativa bem-sucedida de execução da principal função da arte em tempos de fechamento das possibilidades: produzir a visão de outras possibilidades de organização do pensamento e do mundo, que da realização simbólica possam se realizar no devir através da intervenção política.

Entretanto, em 1934-5 as circunstâncias que haviam criado o impulso inicial e posterior desenvolvimento dessas duas experiências não estavam asseguradas. Longe disso, tanto no caso do cinema russo quanto na comedia americana, os florescimentos extraordinários que haviam causado espanto em Benjamin já estavam a caminho da extinção. No caso russo, é o próprio Benjamin que anuncia o problema para os alemães: em 1927, no texto "Sobre a situação presente do filme russo", Benjamin discute como as "condições internas na Rússia" (leia-se, a censura stalinista) criavam dificuldades para o cinema local, do qual já se começava a exigir uma atitude de "conciliação" (BENJAMIN, 1999, p. 12-15).

Já a comédia norte-americana havia sofrido um duro golpe com a entrada do som no cinema em 1930. Os efeitos catastróficos desse processo são anunciados por Brecht, aparecendo de modo contundente no ensaio "Sobre o emprego da música no teatro épico", escrito em 1935 (BRECHT, 2001, pp. 84-90). Neste texto, Brecht faz uma avaliação das experiências com o som realizadas a partir de 1930 e detecta o retrocesso generalizado que caracterizava a prática industrial. Pois no lugar das experiências iniciadas no teatro épico, onde a música, usada autonomamente em relação à cena, tem papel de comentário, concretizando um gestus social em relação aos materiais cênicos, o 
cinema sonoro se limitou em grande parte a um emprego redundante e cosmético do som, quando não simplesmente contrabandeou os textos dos "clássicos" de literatura para a tela.

Para a indústria americana, os altos investimentos necessários para modernizar equipamentos de filmagem e exibição criaram laços de dependência ainda maiores com os bancos de Wall Street, cujo dinheiro financiou a verticalização da indústria, garantindo seu monopólio sobre os setores de produção, distribuição e exibição. O novo nível de respeitabilidade exigido para atrair as parcelas mais endinheiradas do público provocou um saneamento da comédia. A produção de manuais de roteiro, necessários para a padronização da indústria, passou a exigir a acomodação dos quadros cômicos dentro de estruturas narrativas mais convencionais, que respeitassem a construção dramática do enredo e o desenvolvimento psicológico dos personagens. Poucos dos cômicos da era anterior sobreviveriam. Até hoje, o maior texto crítico sobre esse processo é "O filme Kuhle Wampe", escrito por Brecht em 1932, onde ele analisa o efeito da verticalização da indústria sobre a produção independente e o papel da censura na manutenção do controle desse monopólio (BRECHT, 2000, pp. 203-258).

Para Benjamin, portanto, não poderia haver nada de inevitável ou de assegurado no desenvolvimento das técnicas de reprodutibilidade. Pelo contrário, o cenário era de confronto aberto. Entretanto, dialeticamente Benjamin vê as possibilidades que surgem do cenário de catástrofe generalizada: o fim das concepções idealistas da arte e a consciência dos artistas progressistas de que eles são trabalhadores (ou produtores). Nesse sentido, a reflexão sobre a aura vai mesmo além das alusões às alianças entre a arte e o fetiche da mercadoria. Trata-se, na verdade, de enfrentar o fato de que não existe arte exigente sem militância: pois para verem garantidos seus direitos à liberdade criativa e à retomada de experiência ricas do passado, os trabalhadores-artistas devem lutar para a modificação das relações de produção, que nas condições atuais procurarão aprisionar o desenvolvimento das forças produtivas. Sua atuação, portanto, não pode se restringir ao plano "criativo", mas deve trabalhar na modificação do aparato produtivo. Creio ser esse o sentido profundo da conclamação de Benjamin de que diante da estetização da política efetuada pelo fascismo é preciso politizar a arte. Quanto ao papel da crítica, creio que é seu dever não apenas a análise do papel cognitivo da arte exigente a partir do estudo das relações entre forma e conteúdo sócio histórico, mas também a descrição e análise das formas de combate que procuram possibilitar que avanços cognitivos aconteçam.

Em 1929, quando um jornalista alemão fez uma pergunta a Brecht a respeito da possibilidade da introdução gradual das formas épicas no teatro convencional, ele responde categórico: "Não. Se isso acontecer gradativamente, parecerá à plateia que ela vê algo velho morrendo e não algo novo nascendo" (BRECHT, 2001, pp.14-17). Parece que está aqui a explicação da debilidade de grande parte do cinema de esquerda contemporâneo, às vezes repleto de boas intenções liberais. Para a arte de esquerda exigente, vale outra lição de Brecht, com a qual Benjamin certamente concordaria: prevendo o sequestro que seria efetuado das categorias épicas pela arte convencional (que realmente viria a acontecer na França pós-1968, quando as "técnicas" do épico foram transformadas em receituário formalista), o próprio Brecht recomendou que se 
falasse em teatro dialético e, assim, tocou naquilo que, até hoje, a voracidade pósmoderna não conseguiu incorporar para a indústria: a dialética.

\section{REFERÊNCIAS}

BENJAMIN, Walter. Obras escolhidas. Vol. III. São Paulo: Brasiliense, 1994.

Selected Writings. London: Belknap Press, 1999.

BRECHT, Bertolt. Brecht on Film and Radio. New York: Methuen, 2000.

Brecht on Theatre. London: Hill and Wang, 2001.

COSTA, Iná Camargo. Nenhuma lágrima. São Paulo: Nankin, 2012.

JAMESON, Fredric. Marxism and Form. New York: Princeton University Press, 1974.

LOWY, Michael. Walter Benjamin: aviso de incêndio. São Paulo: Boitempo, 2005.

XAVIER, Ismail. A experiência do cinema. Rio de Janeiro: Graal, 1983.

Recebido em: 15/04/2014. Aprovado em 15/06/2014

Title: Technological reproducibility, art and politics

Aythor: Marcos Soares

Abstract: This essays intends to map out some of the key moments of the dialogue between German critic Walter Benjamin and playwright Bertolt Brecht on the potential of film as an artistic language and the risks artists seriously interested in the development of cinema ran with the rise of nazi-fascism.

Keywords: Benjamin. Brecht. Cinema. Reproductibility. Fascism. 